\title{
Discovery, identification, and functional characterization of long noncoding RNAs in Arachis hypogaea L.
}

Haiying Tian ${ }^{1}$, Feng Guo ${ }^{2}$, Zhimeng Zhang ${ }^{3}$, Hong Ding ${ }^{3}$, Jingjing Meng ${ }^{2}$, Xinguo Li ${ }^{1,2^{*}}$, Zhenying Peng ${ }^{1,2^{*}}$ and Shubo Wan ${ }^{1,4^{*}}$

\begin{abstract}
Background: Long noncoding RNAs (InCRNAs), which are typically $>200$ nt in length, are involved in numerous biological processes. Studies on IncRNAs in the cultivated peanut (Arachis hypogaea L.) largely remain unknown.

Results: A genome-wide scan of the peanut (Arachis hypogaea L.) transcriptome identified 1442 IncRNAs, which were encoded by loci distributed over every chromosome. Long intergenic noncoding RNAs accounted for $85.58 \%$ of these IncRNAs. Additionally, 189 IncRNAs were differentially abundant in the root, leaf, or seed. Generally, IncRNAs showed lower expression levels, tighter tissue-specific expression, and less splicing than mRNAs. Approximately $44.17 \%$ of the IncRNAs with an exon/intron structure were alternatively spliced; this rate was slightly lower than the splicing rate of mRNA. Transcription at the start site event was the alternative splicing (AS) event with the highest frequency (28.05\%) in peanut IncRNAs, whereas the occurrence rate (30.19\%) of intron retention event was the highest in mRNAs. AS changed the target gene profiles of IncRNAs and increased the diversity and flexibility of IncRNAs, which may be important for IncRNAs to execute their functions. Additionally, a substantial number of the peanut AS isoforms generated from protein-encoding genes appeared to be noncoding because they were truncated transcripts; such isoforms can be legitimately regarded as a class of IncRNAs. The predicted target genes of the IncRNAs were involved in a wide range of biological processes. Furthermore, expression pattern of several selected IncRNAs and their target genes were examined under salt stress, results showed that all of them could respond to salt stress in different manners.
\end{abstract}

Conclusions: This study provided a resource of candidate IncRNAs and expression patterns across tissues, and whether these IncRNAs are functional will be further investigated in our subsequent experiments.

Keywords: Arachis hypogaea L., Transcriptome analysis, IncRNAs, Alternative splicing, Organ-specific expression, Saltstress

\footnotetext{
* Correspondence: xinguol@163.com; pengzhenying2005@126.com; wansb@saas.ac.cn

${ }^{1}$ College of Life Science, Shandong University, Jinan 250014, China

Full list of author information is available at the end of the article
}

(C) The Author(s). 2020 Open Access This article is licensed under a Creative Commons Attribution 4.0 International License, which permits use, sharing, adaptation, distribution and reproduction in any medium or format, as long as you give appropriate credit to the original author(s) and the source, provide a link to the Creative Commons licence, and indicate if changes were made. The images or other third party material in this article are included in the article's Creative Commons licence, unless indicated otherwise in a credit line to the material. If material is not included in the article's Creative Commons licence and your intended use is not permitted by statutory regulation or exceeds the permitted use, you will need to obtain permission directly from the copyright holder. To view a copy of this licence, visit http://creativecommons.org/licenses/by/4.0/ The Creative Commons Public Domain Dedication waiver (http://creativecommons.org/publicdomain/zero/1.0/) applies to the data made available in this article, unless otherwise stated in a credit line to the data. 


\section{Background}

The central dogma of molecular biology, which proposes the flow of information from DNA to RNA to protein [1], is no longer tenable with mounting number of RNAs not coding proteins. These noncoding RNAs (ncRNAs) have been classified in various ways in accordance with their locations, lengths, and biological functions [2]. Broadly, ncRNAs fall into two categories: house-keeping and regulatory $[2,3]$. The latter can be divided into short ncRNAs $(<200 \mathrm{nt})$ and include short interfering RNAs (20-31 nt), small ncRNAs and long noncoding RNAs (> $200 \mathrm{nt}$, lncRNAs) [4]. Short interfering RNAs include small interfering RNAs, microRNAs (miRNAs), and PIWI-interacting RNAs; these sequences differ across the different eukaryotes where they are found [5]. LncRNAs are categorized into antisense lncRNAs, long intergenic ncRNAs (lincRNAs), and intronic lncRNAs (incRNAs) on the basis of their genomic origin and/or their orientation relative to their neighboring proteinencoding transcripts [3, 6-8].

Undoubtedly, advances in genomics and bioinformatics, particularly the extensive application of nextgeneration sequencing, have boosted the identification and annotation of ncRNAs that have been determined to participate in a range of regulatory roles rather than simply represent transcriptional noise [4-8]. Although lncRNAs might be the least well-studied of these ncRNAs, a growing body of evidence suggests that they exert their functions at the transcriptional, posttranscriptional, and epigenetic levels in fungi, plants, and animals [5, 9-15]. In particular, animal IncRNAs have been associated with aging, hematopoiesis, pri-miRNA processing, muscle differentiation, neural development, and immune responses [16-21]. Xist, one of the beststudied lncRNAs, silences transcription by directly interacting with SHARP, recruiting SMRT, activating HDAC3, and deacetylating histones to exclude Pol II across the $\mathrm{X}$ chromosome during development in female mammals [12]. While studies on plants are limited compared with those on humans and animals, tens of thousands of lncRNAs have been identified via RNA-seq and bioinformatics analyses in several plants, such as Arabidopsis [22], Medicago [23] soybean [9], rice [24], wheat [25], maize [26], tomato [27], mulberry [28], poplar [29], and sea buckthorn [11]. Furthermore, available researches have suggested that a small quantity of lncRNAs perform regulatory functions in plants similar to those in animals [30-32]. For example, the lncRNA COOLAIR, a long intronic noncoding RNA, is required for establishing stable repressive chromatin at FLC through its interaction with PRC2 [31]. In rice, Ding et al. found that the IncRNA long-day-specific malefertility-associated RNA is essential for the normal pollen development of plants grown under long-day conditions [30]. And also, more and more researches suggest that lncRNAs play important roles in the regulation of gene expression in response to various stresses [33-38]. An Arabidopsis lncRNA, DROUGHT INDUCED lncRNA (DRIR), was a new positive regulator of the plant response to drought and salt stress [37]. DRIR expressed at a low level under control conditions but increased significantly under drought and salt stress as well as ABA treatment. And also, drir ${ }^{D}$ mutant or overexpressing DRIR in Arabidopsis could increase tolerance to drought and salt stress of the transgenic plants, RNAseq results demonstrated that DRIR can modulate the expression of a series of genes involved in ABA signaling, water transport, and other stress-relief processes. Although a growing body of evidence supports the diverse potential roles of lncRNAs in plants, studies on lncRNAs in the cultivated peanut (Arachis hypogaea L.) largely remain unknown. Recently, Zhao et al. identified 50,873 lncRNAs of peanut from large-scale published RNA sequencing data, which belonged to 124 samples involving 15 different tissues, and predicted the co-expressions of targeted genes and 386 hub lncRNAs [39].

The peanut is an allotetraploid species derived from natural hybridization between the wild diploids $A$. duranensis and $A$. ipaensis [40]. The peanut ranks sixth among oilseed crops in terms of seed production; approximately two thirds of harvested peanut seed is used for oil production, with the residual seed cake used as a protein-rich meal for livestock $[41,42]$. The genomic sequences of both of the progenitor species of the peanut have now been acquired [43], thus providing an opportunity to analyze the contribution of IncRNAs to the plant's transcription and ultimately to its phenotype. Here, strand-specific sequence data obtained from the peanut were scanned for IncRNA content, and bioinformatics analysis combined with experiment were applied to illustrate the range of biological processes in which lncRNA activity is likely involved. Some new viewpoints were put forward.

\section{Results \\ Peanut Transcriptome analysis}

After trimming adapter sequences and low-quality reads, over $11.14 \mathrm{~Gb}$ of clean data were acquired from each of the four libraries (FH1-seed1, FH1-seed2, FH1-root, and FH1-leaf) for further analysis. The reads were resolved into 203.8 billion paired-end reads with lengths of 125 bp. The individual libraries' $\mathrm{Q}_{30}$ value ranged from 88.90 to $89.79 \%$, and their GC content ranged from 44.48 to 50.48\% (Additional file 1: Table S1). Between 79.91 and $84.16 \%$ of the reads were successfully aligned with the peanut reference genome sequence (Additional file 2: Table S2). In addition, the overall mapping results regarding the distribution of RNA-seq reads in the 
annotated protein coding genes (exonic and intronic) and intergenic regions should be presented in Fig. 1a. The majority of reads $(66.60-74.25 \%)$ were mapped to the exonic sequence, with $<10 \%$ mapping to intronic sequence (Fig. 1a).

\section{Identification of LncRNAs}

A total of 1442 sequences remained after the imposition of the various criteria intended to identify putative lncRNAs (Additional file 3: Table S3); The FPKM values associated with each library suggested that the distribution of lncRNA abundance in the four libraries was broadly similar, although some evidence showed that the FH1-root library differed marginally with respect to their sequence distribution and their abundance (slightly higher) (Fig. 1b). Three types of lncRNA sequences were identified: lincRNAs, incRNAs, and antisense-lncRNAs, and lincRNAs accounted for $85.60 \%$ of the full set (Fig. 1c); of these sequences, 1007 were represented in FH1seed1, 992 in FH1-seed2, 952 in FH1-root, and 917 in FH1-leaf (Fig. 2a). The number of sequences represented in all four libraries was 465, whereas the numbers of library-specific sequences were 86, 75, 78, and 50; 261 of the lncRNAs were specific to the developing seed (specific to either FH1-seed1 or FH1-seed2 or present in both libraries but absent from FH1-root and FH1-leaf).
The number of lincRNAs represented in all four libraries was 387, whereas the numbers of library-specific lincRNAs were 77, 70, 70, and 42 (Fig. 2b). Substantial numbers of organ-specific intronic-RNAs and antisenselncRNAs were also recognized (Fig. 2c, d). A total of 189 of the lncRNAs were classified as differentially abundant lncRNAs (DALs; Fig. 3; Additional file 4: Table S4). The number of DALs represented in all four libraries was 20 , whereas the numbers of library-specific sequences were 16, 16, 11, and 3 (Fig. 2e).

\section{Genomic distribution of LncRNAs}

The set of identified lncRNAs was transcribed from sequences distributed across all 20 chromosomes of the peanut genome, although a higher number was associated with the B subgenome than with the A subgenome chromosomes (863 vs 579, Additional file 5: Table S5). Chromosome Araip.B02 transcribed 112 of the identified lncRNAs against the 31 transcribed from chromosome Aradu.A07. The mean number of lncRNAs per hundred genes within the A subgenome was 2.57 , whereas the equivalent statistic for the B subgenome was 3.37. The correlation between the number of IncRNAs and the number of transcribed genes (based on an FPKM threshold of 0.1) transcribed from each chromosome was + 0.61 (significant at $P<0.01$ ).

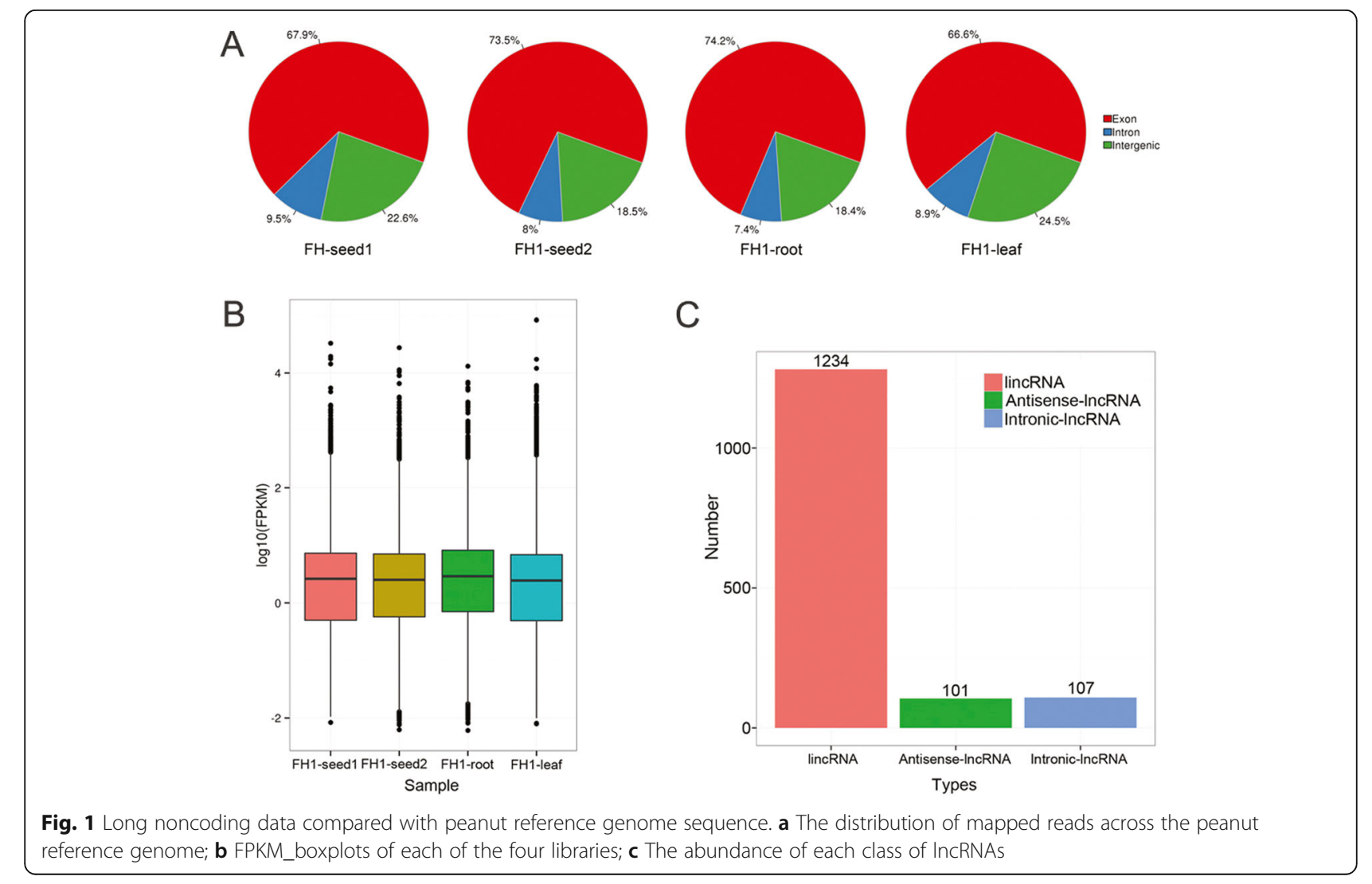



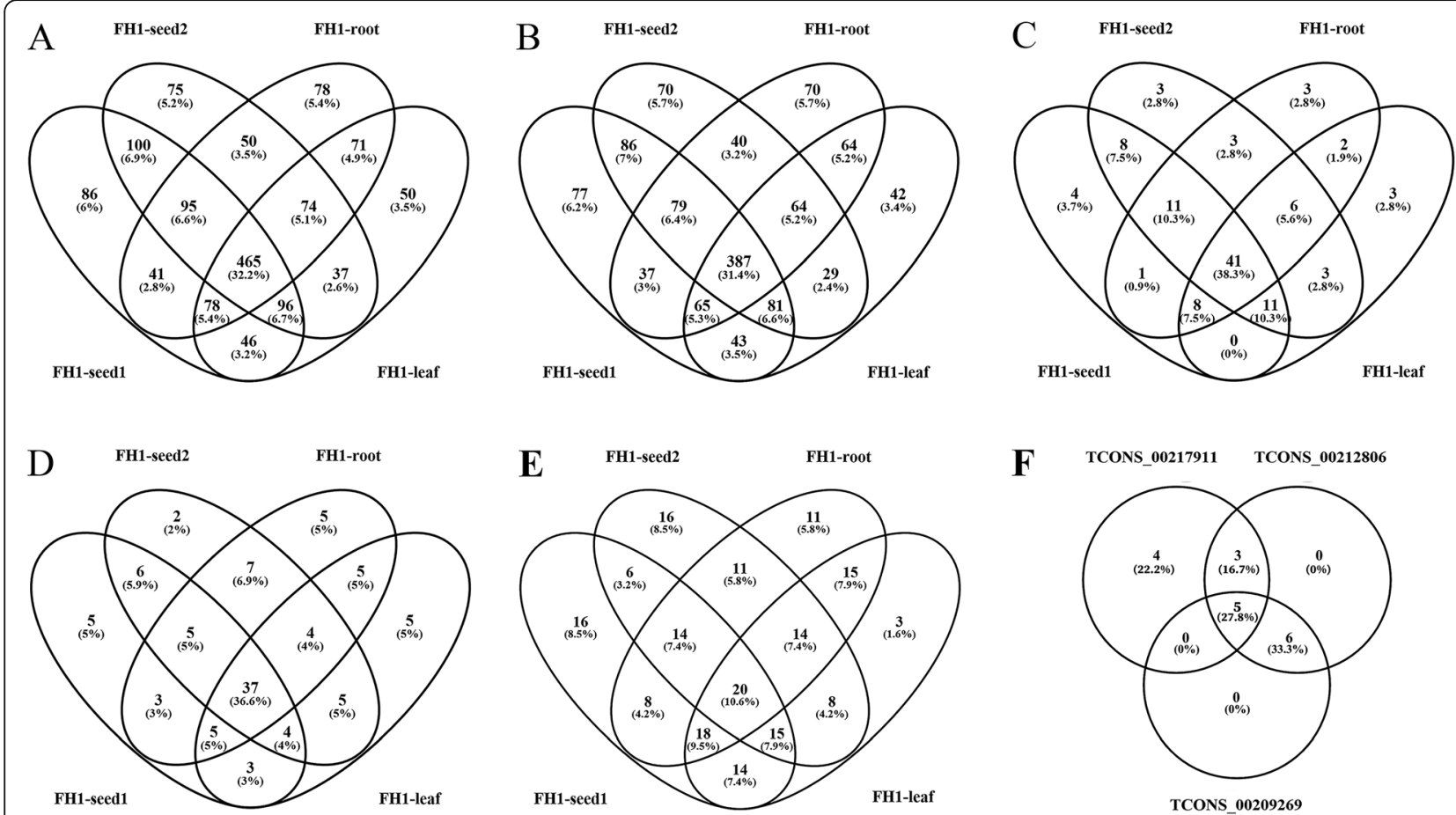

Fig. 2 Overlap and uniqueness of the IncRNAs between organs. a The full set of IncRNAs; $\mathbf{b}$ lincRNAs; $\mathbf{c}$ intronicRNAs; $\mathbf{d}$ antisense-IncRNAs; e DALS

\section{Comparison between mRNAs and LncRNAs}

The sequences of 213,515 transcripts, generated from 55,621 genes, were acquired: this set of sequences, which included AS isoforms, is collectively referred here to "mRNAs". The mean length of the mRNAs was $2017 \mathrm{nt}$, with the majority of their lengths falling in the range of 400-2600 nt (Fig. 4a), whereas the equivalent lengths of the lncRNAs were $1074 \mathrm{nt}$ and $400-1400$ nt. (Fig. 4b). The mean length of the open reading frames (ORFs) of the mRNAs was $240 \mathrm{nt}$, with the majority falling within the range of 100-300 nt, whereas that of the lncRNAs was $96 \mathrm{nt}$, with the length ranging from $50 \mathrm{nt}$ to $150 \mathrm{nt}$ (Fig. 4c, d). All of the lncRNAs, which included at least one intron, had fewer exons with a mean exon number of 2.77 than the mRNAs, which had a mean exon number of 5.48 (Fig. 4e, f). The abundance of the mRNAs was generally higher than that of the lncRNAs (Fig. 4g). The mRNAs generated a greater number of AS isoforms than did the lncRNAs (Fig. 4h).

\section{Predicting the target genes of the LncRNAs}

To investigate the potential functions of the lncRNAs, their target genes were examined in cis (Additional file 6: Table S6) and in trans (Additional file 7: Table S7). All the target genes were annotated with their integrated function on the basis of five protein databases. A total of 11,765 target genes were obtained (Additional file 8: Table S8), with 9326 in FH1-seed1, 9415 in FH1-seed2,
8742 in FH1-root, and 8497 in FH1-leaf. Among these annotated target genes, 6550 were annotated in the COG database, 4209 in the GO database, 1922 in the KEGG database, 4422 in Swiss-Prot, and 10,019 in NR. Differential expressed target genes (DETGs) between these four libraries were analyzed, and the GO terms were used as an example to analyze the functional classification of the DETGs. In total, 49,706 unigenes were assigned GO terms, and the enriched terms differed in diverse tissues (Fig. 5). The number of DETGs enriched between FH1-seed1 and FH1-seed2 was 244 (Fig. 5a), with 367 between FH1-root and FH1-leaf (Fig. 5b), whereas the number of DETGs enriched between FH1root and FH1-seed1\&FH1-seed2, FH1-leaf and FH1seed $1 \&$ FH1-seed 2 were 50 and 54 , respectively (Fig. 5 c, d). All the GO terms were classified into three major categories (biological process, cellular component, and molecular function), implied that lncRNAs might well be important for the regulation of a wide range of biological processes.

\section{Experimental validation of LncRNAs}

In order to verify the reality of the predicted IncRNAs, seven of the lncRNAs (lncRNA1-7) were validated through PCR (Additional file 9: Table S9). The results of Sanger sequencing showed that five sequences identity with the relevant IncRNA sequence was very high (99.33-99.86\%) except two (lncRNA1 and lncRNA2, Additional file 11: Fig. 


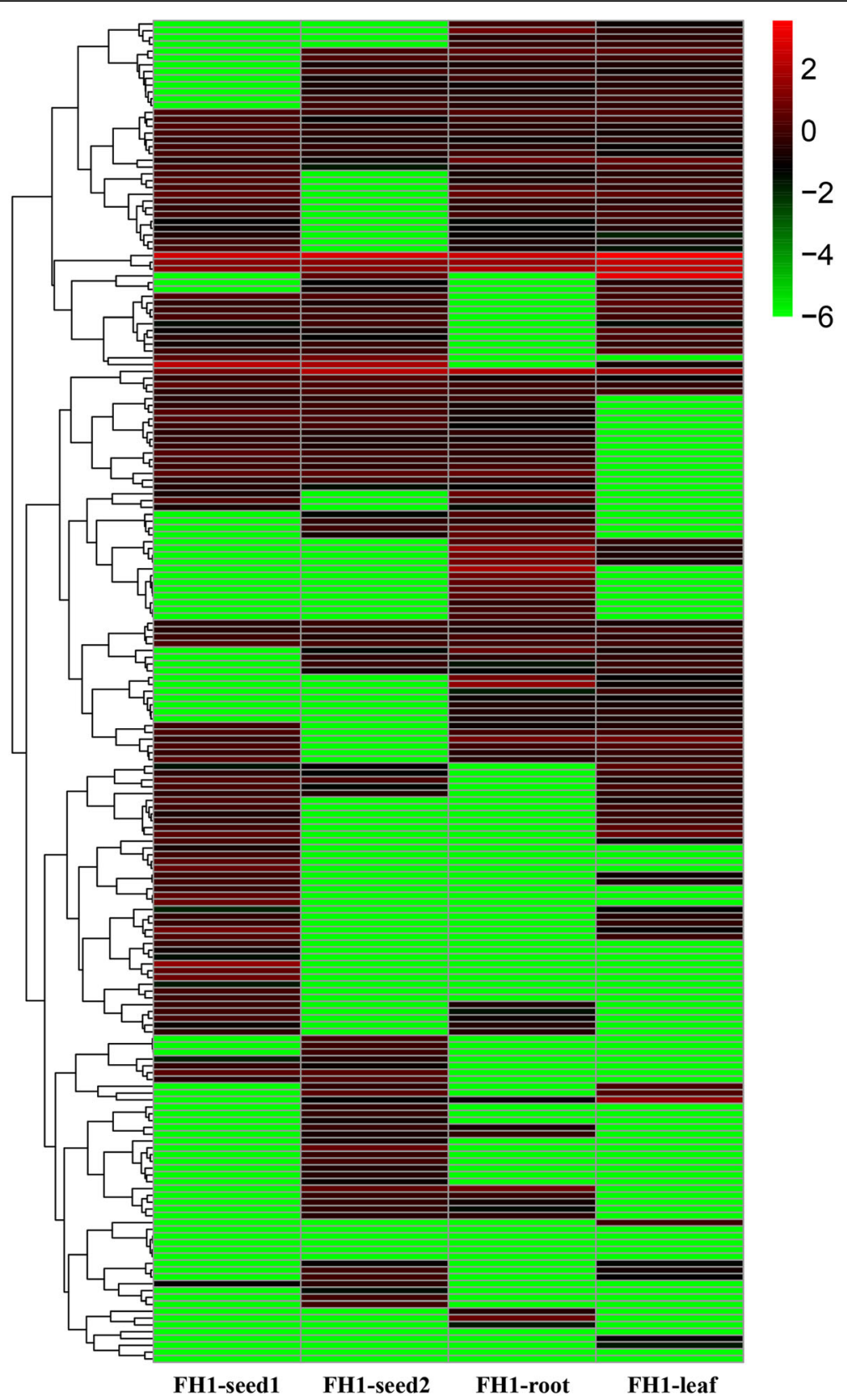

Fig. 3 The abundance of the DALs across organs. The columns of the heat map represent each of the four libraries and the rows show the 189 DALs. The abundance of the DALs is indicated by the intensity of the color

S1). When the PCR sequenced lncRNA1-7 were aligned to the corresponding genomic sequences of $\mathrm{A}$ and $\mathrm{B}$ subgenomes, six of them (except lncRNA1) were well matched the predicted position on the corresponding chromosomes (Additional file 11: Fig. S1) LncRNA1 that shared only 85.68\% identity with TCONS_00179561; a Blastn search of the genomic sequence located a highly homologous sequence (sequence identity: 99.6\%) on Aradu.A03 in segment 130,713,152-130,713,435, whereas TCONS 00179561 was located in Araip.B03 131,673,533-131,674,
406; thus lncRNA1 could not have been a product of TCONS_00179561, maybe PCR amplified its homologous genes. LncRNA2 shared $96.84 \%$ identity with TCONS_ 00109592. Blastn search located this sequence in the expected chromosome position (TCONS_00109592) but highlighted a $9 \mathrm{nt}$ indel and several nucleotide polymorphisms between the genomic sequence and the lncRNA. We speculated that the product might be an AS isoform of IncRNA2. The differences between LncRNA3-7 and the corresponding genomic sequences were $1,1,2,1,6$ 

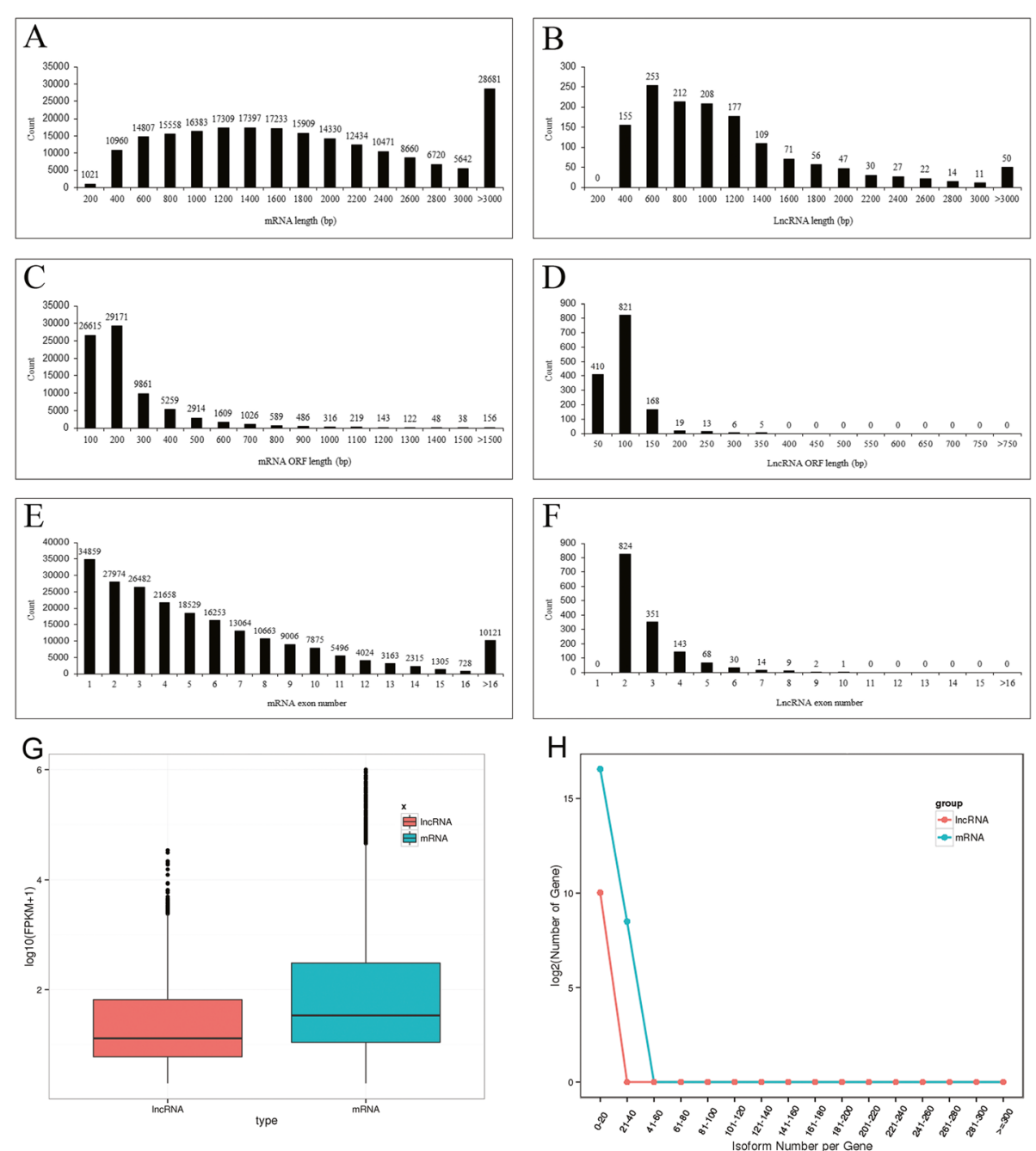

Fig. 4 The population of peanut mRNAs and IncRNAs. a vs $\mathbf{b}$, comparisons of transcript length; $\mathbf{c} v s \mathbf{d}$, ORF length; e vs $\mathbf{f}$, exon number; $\mathbf{g}$ transcript abundance; $\mathbf{h}$, isoform density. The number on the bar (a-f) above the bar shows the transcript number

nucleotides, respectively. For lncRNA4, the nucleotide is $\mathrm{T}$ at $609 \mathrm{nt}$ of the cloned sequence as well as A01 subgenome and the nucleotide in RNA-seq was C. So, the discrepancy may well be due to the sequencing error in RNA-seq. For the others, the difference should be a result of sequencing error PCR amplification, because the sequences in RNAseq were the same as their subgenomes (Fig. S1). Simply put, these differences maybe come from sequencing error, or PCR amplification. The successful validation of six out of the seven lncRNAs indicated that the prediction of the majority of the lncRNAs was credible.

\section{AS events of LncRNAs}

Comparing the lncRNA and genomic DNA sequences suggested that AS is likely involved in their transcription. On the basis of the RNA-seq data, five AS events (transcription start site, TSS; transcription terminal site, TTS; exon skipping, ES; intron retention, IR; alternative exon, AE) were investigated (Table 1). Overall, 1811 AS events were involved in 637 lncRNAs, accounting for approximately $44.17 \%$ of the identified 1442 lncRNAs. Meanwhile, approximately $47.82 \%$ of mRNAs produced alternative transcripts; this rate is higher than that for lncRNAs. TSS was the AS event with the highest frequency $(28.05 \%)$ in peanut lncRNAs, whereas the occurrence rate $(30.19 \%)$ of IR was highest in mRNAs. Additionally, the frequency of the ES event was the lowest in lncRNAs and mRNAs.

Using the genomic segment $94,398,232-94,402,918$ on chromosome Araip.B05 as an example, three lncRNAs (TCONS_00217911, TCONS_00212806, TCONS_002 09269) (Additional file 3: Table S3) were speculated as a group of AS isoforms and verified by PCR test. Five transcripts, namely T1-T5, were sequenced (Fig. 6, Additional file 11: Fig. S2). T1 was identical to TCONS 00217911, T2 was an isoform of TCONS_00217911, and 


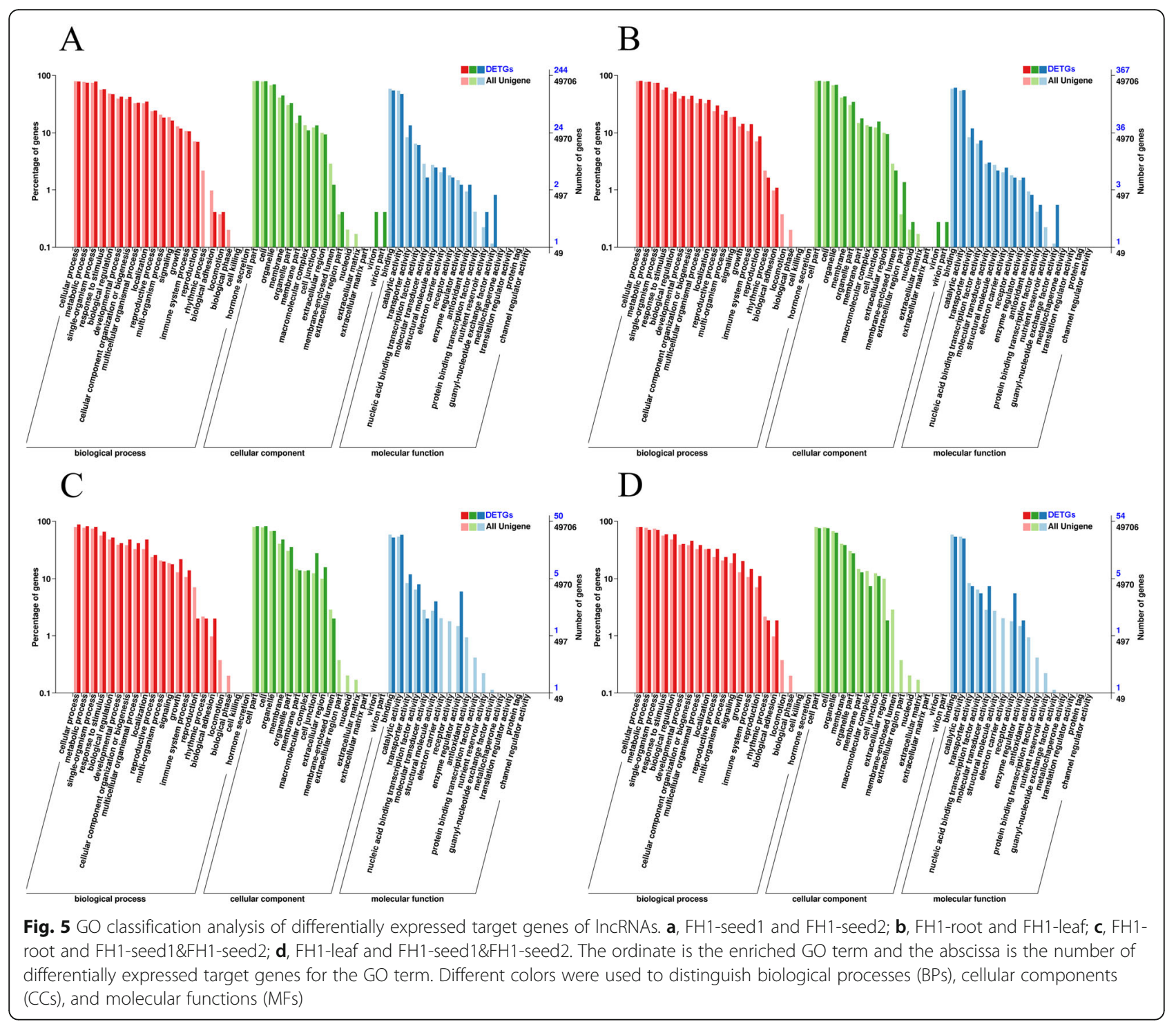

a TSS event was happened. T3 and T4 were AS isoforms of TCONS_00212806, and TSS and ES events were happened. T5 was an AS isoform of TCONS_00209269, and IR and ES events were happened. These alignments

Table 1 The comparison of AS events between IncRNAs and mRNAs

\begin{tabular}{llllll}
\hline AS & IncRNA & & & mRNA & \\
\cline { 2 - 3 } \cline { 6 - 6 } Types & AS events & Percentage & & AS events & Percentage \\
\hline TSS & 508 & $28.05 \%$ & & 16,942 & $19.87 \%$ \\
TTS & 478 & $26.39 \%$ & & 13,914 & $16.32 \%$ \\
ES & 39 & $2.15 \%$ & & 10,791 & $12.65 \%$ \\
IR & 340 & $18.77 \%$ & & 25,748 & $30.19 \%$ \\
AE & 446 & $24.63 \%$ & & 17,880 & $20.97 \%$ \\
Total & 1811 & $100.00 \%$ & & 85,275 & $100.00 \%$ \\
\hline
\end{tabular}

demonstrated that AS was a universal phenomenon in lncRNA, and may play important roles in their function regulation.

Another phenomenon was found related to the AS events of lncRNAs; that is, different AS isoforms of one lncRNA have different target genes. For example, the target genes of three IncRNAs (TCONS_00217911, TCONS_00212806, TCONS_00209269) were used for comparison. All of them have no cis-target genes (Additional file 6: Table S6) but have many trans-target genes (Additional file 7: Table S7). Each of them has 12, 14, and 11 trans-target genes, respectively. There were five trans-target genes belonged to three of them. Eight similar trans-target genes belonged to TCONS_00217911 and TCONS_00212806; five similar trans-target genes belonged to TCONS_00217911 and TCONS_00209269; 


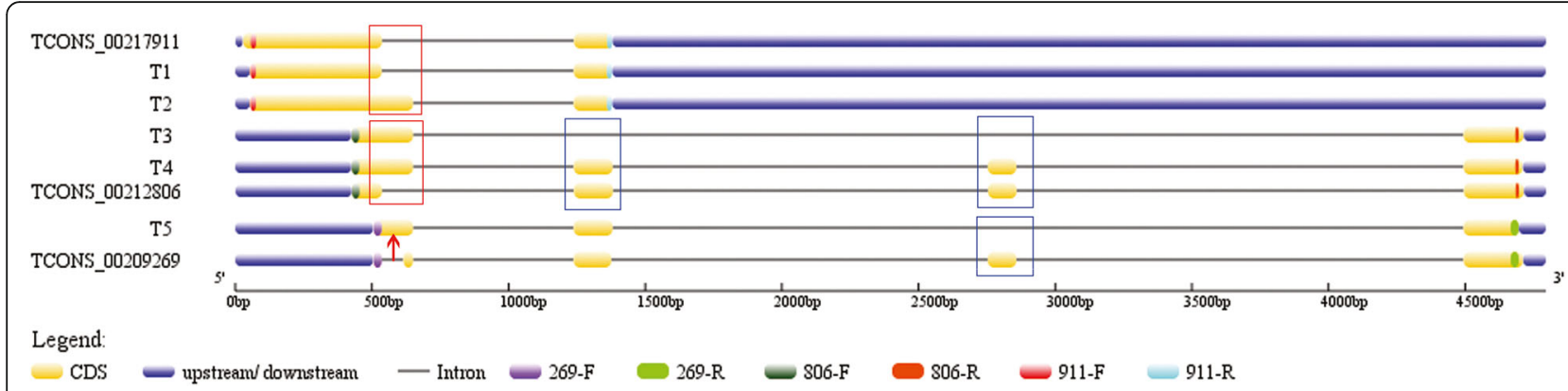

Fig. 6 Identification of the AS isoforms of peanut IncRNAs. Gene structures of IncRNA AS isoforms. T1-T5: PCR products from Sanger sequencing; TCONS_00217911, TCONS_00209269 and TCONS_00212806 from the RNA-seq. Red rectangles indicate TSS type and blue ones show ES type. The red arrow shows IR type

11 similar trans-target genes belonged to TCONS_ 00209269 and TCONS_00212806. Only TCONS 00217911 had four specific target genes (Fig. 2f). Other examples included TCONS_00011553, TCONS_ 00013006, and TCONS_00013007, which were all located on genome Aradu.A01 (99975619-99,981,506, Additional file 3: Table S3). The results of gene structure analysis showed that they had different AS isoforms (Additional file 12: Fig. S3A), and a total of 29 target genes were found (Additional file 6: Table S6, Additional file 7: Table S7). Among these target genes, 26 were represented in three of them, whereas only TCONS 00013006 had no specific target genes and the other two had only one (Additional file 12: Fig. S3B). AS can change the target-gene profiles of lncRNAs and increase the diversity and flexibility of lncRNA. This may be an important way for lncRNAs to execute their function.

\section{Protein-encoding genes as a source of LncRNAs}

Not all AS isoforms encode a protein and are noncoding to a certain extent. A substantial number of the peanut AS isoforms generated from protein-encoding genes appeared to be noncoding because they were truncated transcripts; such isoforms can be legitimately regarded as a class of lncRNA. Several papers reported that approximately one-third of the alternative transcripts were likely noncoding $[44,45]$. Here, a protein-encoding gene Aradu.Z4DIZ, which generates five transcripts, was selected as an example for validating this point (Fig. 7, Additional file 13: Fig. S4). Only two of the AS products (Aradu.Z4DIZ.1 and Aradu.Z4DIZ.3) were predicted to encode complete proteins. The Sanger sequencing results of the amplified product generated from a primer pair directed at this gene revealed the presence of five isoforms: L1.5 matched Aradu.Z4DIZ.4 given that both transcripts lacked the seventh exon. L1.1 encoded 232

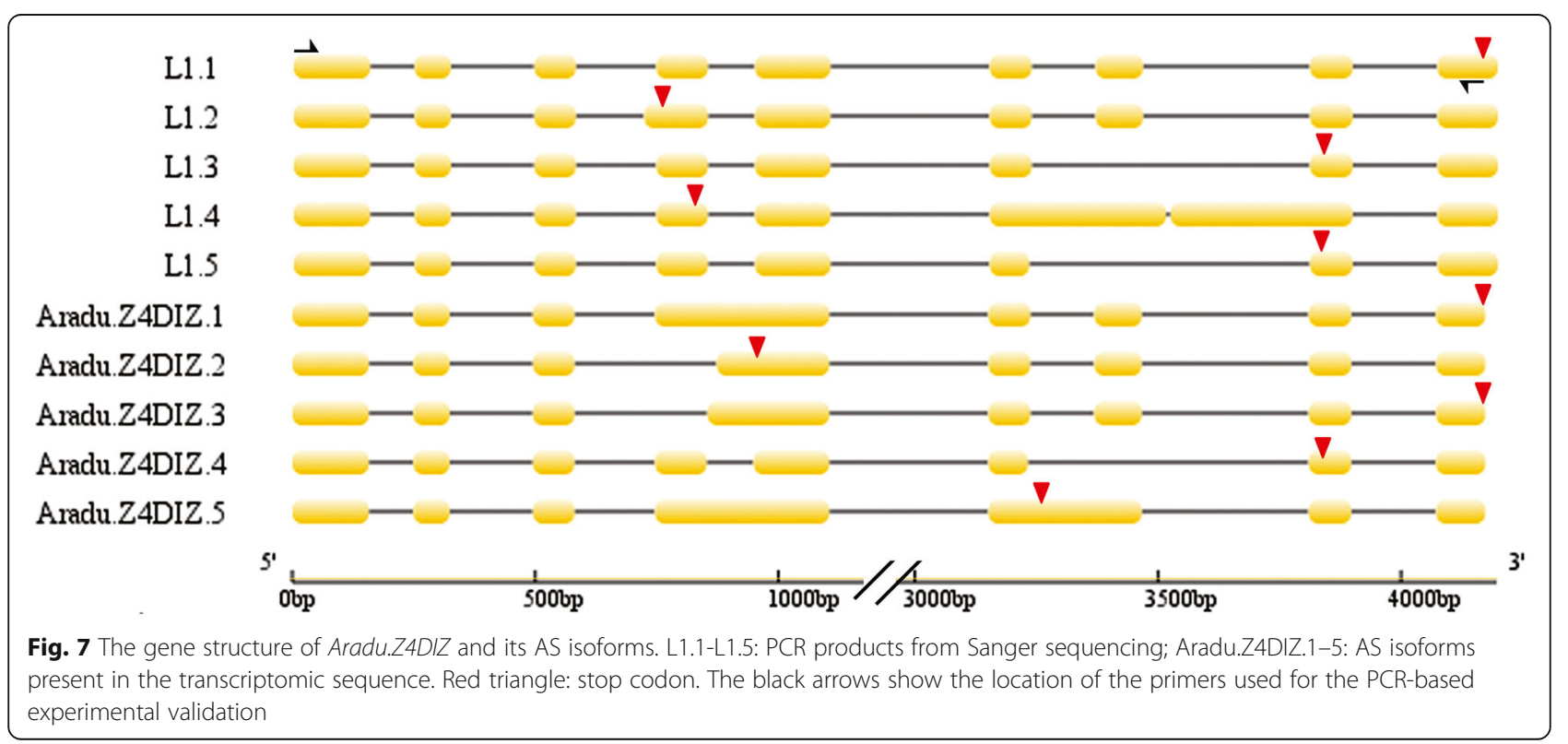


amino acids (aa) and was 18 residues shorter than the predicted Aradu.Z4DIZ.1 product. L1.2 encoded 118 aa, L1.4 encoded 177 aa, and L1.3 encoded 240 aa; the three encoded proteins were incomplete. The predicted product of Aradu.Z4DIZ is a diacylglycerol O-acyltransferase that carries a conserved LPLAT domain within its Cterminus; the truncated transcripts all lack the determinants of a complete LPLAT domain. This characteristic thereby compromises the functionality of their translation product.

\section{Validation of expression level of IncRNAs by qRT-PCR}

To validate the abundance of lncRNAs, eight lncRNAs (lncRNA8-15) were randomly selected and analyzed through qRT-PCR (Additional file 9: Table S9). As shown in Fig. 8, the expression patterns of these lncRNAs were relatively consistent with RNA-seq results; this consistency indicated that the lncRNA expression patterns based on RNA-seq data are reliable.

\section{Coexpression of LncRNAs and their target genes by RT- PCR}

One lncRNA can interact with several gene targets and vice versa (Additional file 14: Fig. S5). Five lncRNAs (lncRNA16-20) and their target genes (Additional file 9:
Table S9) were selected to verify the relationships between IncRNA and mRNA, the relative position of the five lncRNAs and their target genes are shown in Fig. 9a. TCONS_00176941 was located far from its two target genes at 8.2 and $9.5 \mathrm{~Kb}$ upstream and downstream, respectively. In all of the six organs, the expression level of TCONS_00176941 was higher than that of its two target genes (Fig. 9b). TCONS_00015630 was close to its two target genes downstream (Fig. 9a), and showed similar expression pattern with Aradu.8P876 in the six organs (Fig. 9c). TCONS_00011551 had three cis-target genes and one trans-target gene which showed different expression patterns in the six organs (Fig. 9a, d). TCONS_00292946 and its two target genes showed similar expression patterns in stems, leaves, flowers, and seeds at 30 day after flower (DAF) and in seeds at 50 DAF (Fig. 9e). TCONS_00243464 and its three target genes showed different expression patterns in six organs (Fig. 9f).

\section{Expression pattern analysis of LncRNAs and its target genes under salt stress}

LncRNAs play important role in stress resistance. Here, three lncRNAs and their target genes (Additional file 9: Table S9) were selected to test their expression patterns
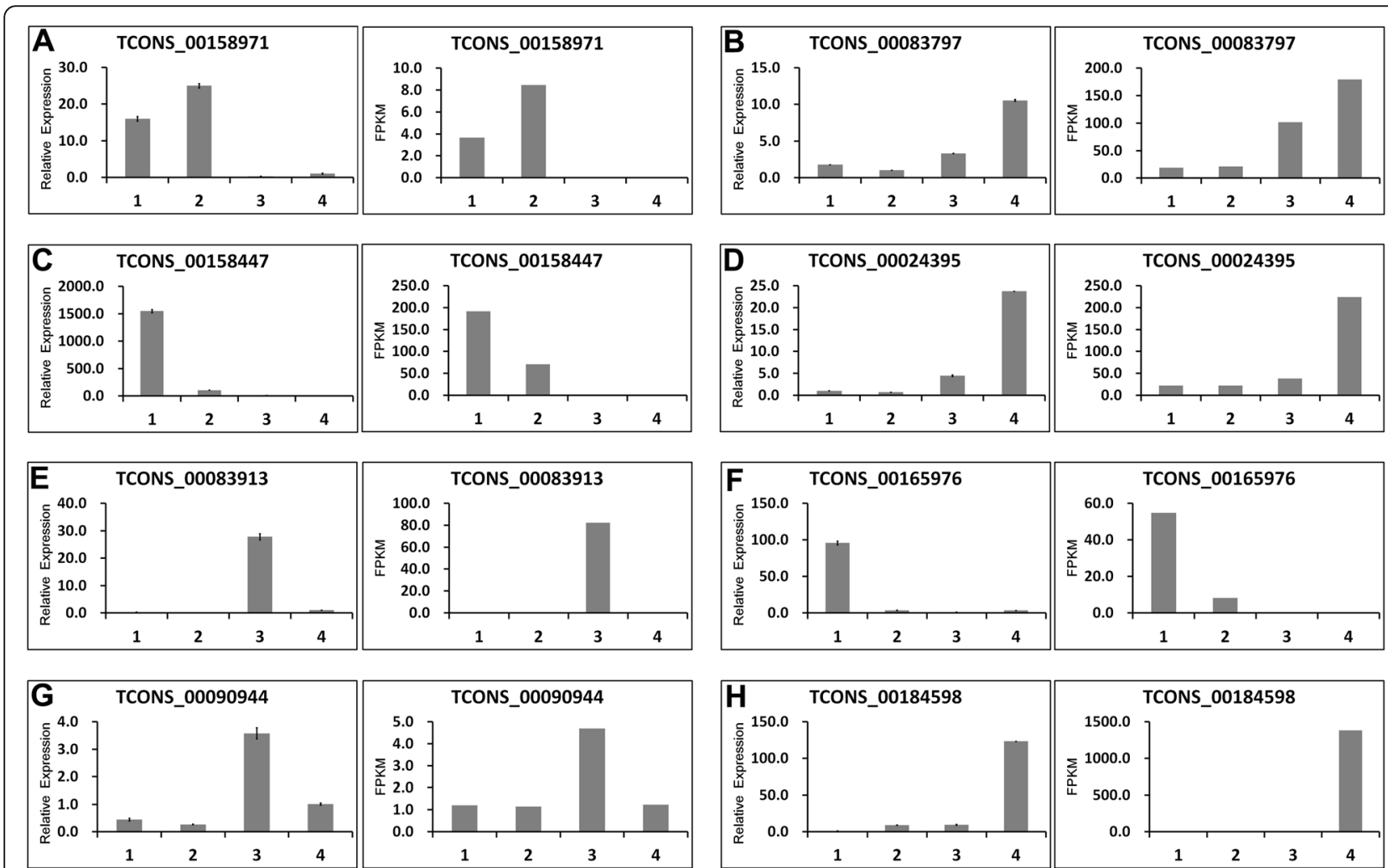

Fig. 8 Validation of IncRNA expression using qRT-PCR. The abundance of each IncRNAs was deduced from RT-qPCR data (left-hand column) and from the RNA-seq data (right-hand column). The number 1, 2, 3, and 4 in the tissue label indicated FH1-root, FH1- leaf, FH1-seed1 nd FH1-seed2, respectively 


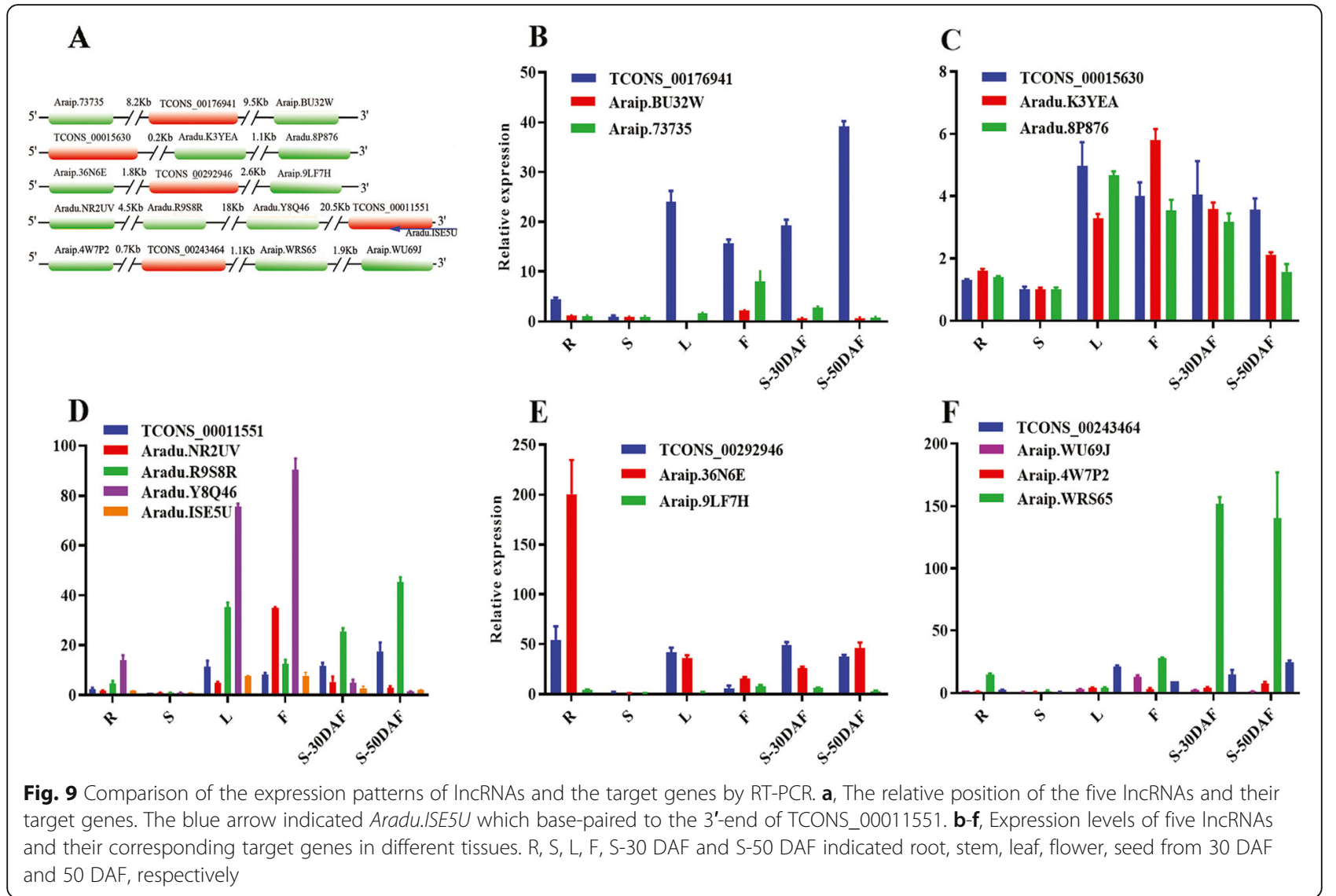

in different organs under salt stress using qRT-PCR (Fig. 10). These target genes were stress-related and with different expression level under salt stress, so the corresponding lncRNAs were selected for salt stress analysis. Results showed that these three IncRNAs and their target genes showed different expression patterns for salt treatment. In the roots, the expression level of TCONS 00292946 decreased within $12 \mathrm{~h}$ and then increased at $24 \mathrm{~h}$ (Fig. 10a). In the leaves, the expression level fluctuated (Fig. 10d). TCONS_00176941 showed opposing expression levels in the roots and leaves (Fig. 10b, e). The expression level of TCONS_00011551 slowly increased along with salt tress (Fig. 10c), but the expression level fluctuated in the leaves (Fig. 10f).

LncRNAs and their target genes showed different expression patterns in response to salt stress. TCONS 00292946 and its two target genes showed similar expression patterns in the roots (Fig. 10a) and opposing expression patterns in the leaves (Fig. 10d). TCONS 00176941 and Araip.BU32W showed similar expression patterns in the roots (Fig. 10b) and different expression patterns in the leaves (Fig. 10e). TCONS_00011551 and Aradu.ISE5U showed similar expression patterns in the roots and leaves, whereas TCONS_00011551 and Aradu.Y8Q46 showed different expression patterns in the leaves (Fig. 10c, f). The action mode of these lncRNAs in response to salt stress will be further studied.

\section{Discussion}

Improvements in nucleotide sequencing technology have revealed the existence of lncRNAs, some of which act as the regulators of a range of eukaryotic cellular processes $[15,37,46-48]$. The number of lncRNAs identified by transcriptomic analyses reflects the depth of the sequencing method applied. A set of $>13,000$ Arabidopsis lncRNAs [2], > 20,000 maize lncRNAs [26], and $>2000$ rice lncRNAs has been reported [49]. Here, a survey of the peanut transcriptome revealed 1442 lncRNAs. By comparing our results with the published peanut lncRNAs of Zhao [39], in which 50,873 lncRNAs of peanut were identified from 124 samples involving 15 different tissues, we found 39 lncRNAs were identical, accounting for about 2.7\% (data shown in Table S10). The low number of identified sequences may simply reflect the small scale of the experiment, which involved only four libraries as opposed to the 124 libraries underlying the above set of IncRNAs in Zhao's [39]. In addition, the selection criteria applied here were more stringent than those commonly used. For example, by removing the restriction placed on the number of exons, 


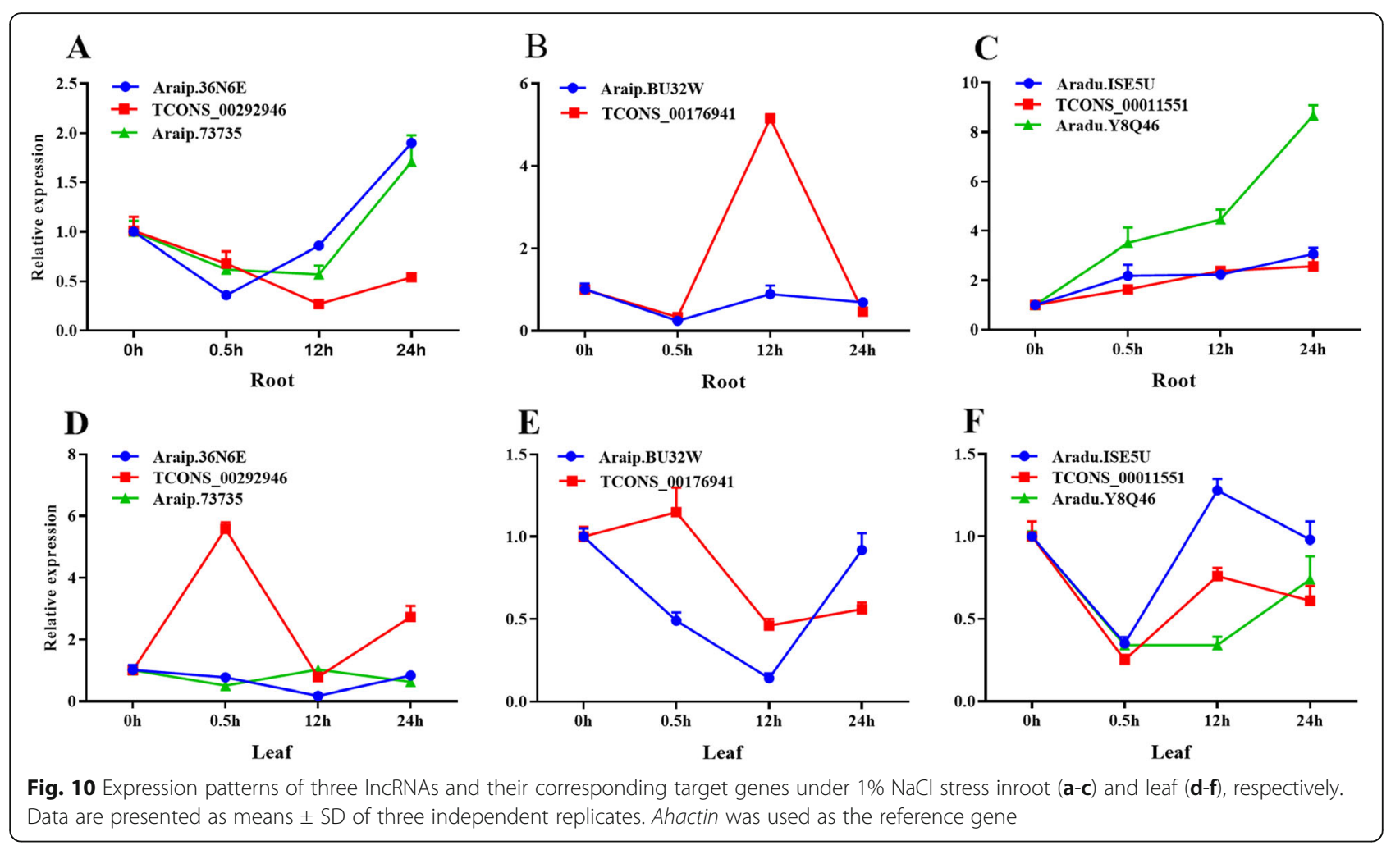

$>10,000$ lncRNAs would have been predicted (data not shown), among which a large number would have been false positives. When a small sample (seven sequences) of the set of lncRNAs was subjected to PCR-based validation, $>70 \%$ proved to be genuinely represented in the peanut transcriptome.

AS is adopted universally for post-transcriptional gene regulation $[50,51]$. In plants, it is deployed to control aspects of growth, development, signal transduction, flowering, circadian clock function, and environmental cue responses [49, 52-55]. Similar to protein-encoding genes, the transcribed sequences for numerous lncRNAs developed AS variants in animals and plants [56-58]. For example, lncRNA-PXN-AS1, which lacks exon 4, binds to the coding sequences of PXN mRNA and inhibits PXN mRNA translation. By contrast, lncRNAPXN-AS1, which contains exon 4, preferentially binds to the 3' untranslated region of PXN mRNA, protects PXN mRNA from degradation, and thereby increases PXN expression [58]. Here, a number of AS isoforms were predicted from peanut RNA-seq data, and experiments via PCR validated these isoforms were real (Figs. 6, 7). Like AS of protein-coding genes, all kinds of AS types of protein-coding genes were found in lncRNAs (Table 1), but remarkable difference was also existed. We found that IR was the most occurred AS events in mRNA, with TSS the highest frequency in lncRNAs. AS events of lncRNAs can also increase the diversity of lncRNAs. It can change the target genes of a lncRNA (Fig. 2f, Additional file 12: Fig. S3), thus increase the flexibility of lncRNA. It may be an important regulation of lncRNAs.

Additionally, numerous protein-encoding genes transcribe diverse variants; several of these transcripts are unable to encode a functional protein because they represent the truncated forms of a fully functional mRNA (Fig. 7). These sequences could be regarded as another class of lncRNAs or pseudogene-derived lncRNAs in some sense [59]. Protein-coding mRNA transcripts can crosstalk with other mRNA transcripts by competing for common microRNAs [59]. The pseudogene PTENP1 has been hypothesized to be biologically active in prostate cancer cells by competitively binding to miR-17, miR-19, miR-21, and miR-26 families to regulate the cellular levels of PTEN and exert a growth-suppressive effect [60]. LncRNAs that were thought not to encode proteins could also translate small polypeptides to exert their function but not through the lncRNA itself $[61,62]$. For example, Anderson et al. discovered a conserved micropeptide encoded by a skeletal muscle-specific RNA that was annotated as a putative lncRNA plays an important role in muscle performance [16]. Similarly, experimental evidence exists for the production of functional truncated polypeptides from AS variants derived from a protein-encoding gene. For example, the A. salina CCA1 generates two isoforms, one of which is a full-size transcript $(C C A 1 \alpha)$, whereas the other is a truncated form 
$(C C A 1 \beta)$ that lacks a functional N-terminal MYB DNAbinding domain [63]. The latter transcript inhibits CCA1 $\alpha$ and LATE ELONGATED HYPOCOTYL transcription factors by forming nonfunctional heterodimers and is modulated by low temperatures. The human USP2 gene generates seven AS variants, two of which are not translated into a functional protein [64]. The zebrafish gene LGP2 forms three AS transcripts, of which only the full length version can confer protection against viral infection [65]. The distinction between coding and noncoding RNA is not as sharp as previously thought. Some protein-encoding genes generate noncoding AS variants, which can be recognized as lncRNAs; these sequences may be involved in gene regulation. With technological progress and unremitting effort, additional possible regulatory mechanisms of lncRNAs will be explicitly studied.

A growing body of research suggests that lncRNAs play important roles in plant stress resistance [33-36, $38,47]$. In this study, some peanut lncRNAs with the target genes were tested under salt stress, and the results showed that all of them changed their expression levels (Fig. 10). In poplar, more than 10,000 lncRNAs were identified, and approximately $40 \%$ of them responded to salt stress with tissue-specific expression patterns [34]. In cotton, lncRNA973 was localized in the nucleus and increased by salt treatment. The overexpression of lncRNA973 in Arabidopsis could increase salt tolerance, whereas the knockdown of lncRNA973 in cotton could reduce salt tolerance [36]. Furthermore, many studies reported that IncRNAs play important roles in plant defense against pathogens [66-68]. In tomato, a plausible model for TYLCV-induced diseases and host antiviral immunity was uncovered; that is, lncRNAs interact with the IR-derived vsRNAs to control disease development during TYLCV infection, which provide an effective strategy for the control of plant viral pathogens [67]. In rice, the connection between lncRNAs and the JA pathway in the regulation of bacterial blight was confirmed, which provided a novel insight into plant disease resistance [68]. IncRNAs have three salient features: low expression, lack of conservation between species, and tissue-specific expression patterns [23]. These features indicated that specific prevention and cure methods can be developed for a specific disease, according to specific species and lncRNAs. This will be a development direction for plant disease resistance research in the future.

\section{Conclusion}

We identified 1442 lncRNAs in peanut transcriptome with strand-specific RNA-Seq technique. Among them, 189 lncRNAs were differentially abundant in the root, leaf, or seed. Approximately 44.17\% of the lncRNAs with an exon/intron structure was alternatively spliced. This rate was slightly lower than the splicing rate of mRNA. AS changed the target-gene profiles of IncRNAs and increased the diversity and flexibility of lncRNAs. This may be an important way for lncRNAs to execute their functions. Additionally, protein-encoding genes produced many truncated transcripts by AS, which may be another source of lncRNAs. Some lncRNAs and their target genes were selected for salt response experiments. The results showed that all of them could respond to salt stress in different manners. Identification of peanut lncRNAs will have a strong impact on peanut development, growth, and stress resistance breeding.

\section{Materials and methods Materials}

Peanut plants (cultivar 'Fenghua-1') were grown in a growth chamber with a photoperiod cycle of $16 \mathrm{~h}$ light at $26^{\circ} \mathrm{C}$ and $8 \mathrm{~h}$ dark at $24{ }^{\circ} \mathrm{C}$. Roots and leaves were collected from 12-day-old seedlings (names as FH1-root and FH1-leaf), and developing seeds were collected from plants at 30 days after flowering (DAF) (named as FH1seed1) and 50 DAF (named as FH1-seed2).

\section{Library construction and sequencing}

Total RNAs were isolated from FH1-root, FH1-leaf, FH1-seed1 and FH1-seed2 samples. Whole transcriptome library preparation and deep sequencing were performed as previously described [69]. Briefly, whole transcriptome libraries were prepared using NEBNext ${ }^{\circ}$ Ultra $^{\text {Tm }}$ Directional RNA Library Prep kit (New England Biolabs, Ipswich, MA, USA) following the manufacturer's recommendations. Ultimately, sequencing was performed by imposing a paired-end 125 cycle rapid run on a HiSeq2500 platform (Illumina, San Diego, CA, USA). The raw data were deposited in the NCBI sequence read archive (http://www.ncbi.nlm.nih.gov/sra) with project PRJNA354652.

\section{Transcriptome assembly}

Sequence data were stripped of adapter sequences and low-quality reads. The sequence data acquired from each library were aligned separately with peanut genome sequences [43] (https://www.peanutbase.org/) using TopHat2 software [70]. The aligned reads were assembled into a full transcriptome using the Cufflinks v2.2.1 program [71].

\section{Genome-wide identification of LncRNAs and alternative splicing events in peanut}

The assembled transcripts were annotated using the Cuffcompare facility (http://cufflinks.cbcb.umd.edu/). Transcripts with lengths of more than $200 \mathrm{nt}$ and at least two exons were selected as lncRNA candidates. Subsequently, the transcripts were analyzed using the coding 
potential calculator $($ score $<0)$ [72], the codingnoncoding index (score $<0$ ) [73], the coding potential assessment tool [74], and Pfam (E-value <0.001) [75] to remove all likely remaining protein-encoding genes. Only sequences that passed all of these four scans were considered as likely lncRNA candidates. Alternative splicing (AS) events were identified using ASTALAVISTA program (http://genome.crg.es/astalavista/). The diverse categories of AS events (TSS, TTS, ES, IR and AE) [76] were identified using a Perl script developed in house.

\section{Target gene prediction and functional annotation}

Whether the lncRNAs acted in cis or in trans was predicted. The putative functions of the target genes were also predicted. Coding genes lying within $100 \mathrm{~kb}$ either at the $5^{\prime}$ upstream or $3^{\prime}$ downstream of each IncRNA were identified as potential cis targets [77] on the basis of whether the Pearson and Spearman correlation coefficients between the expression levels of these genes were $\geq 0.6$ or $\leq-0.6$, and $P<0.05$, whereas potential trans targets were predicted with Pearson correlation $\mathrm{r}>0.9, \mathrm{P}<0.05$; a gene coexpression network was constructed using the LncTar program [78], which searches for sequence complementarity between mRNAs and lncRNAs. Subsequently, the target genes were subjected to functional annotation analysis using the following databases: NCBI nonredundant protein sequences [79], KOG/COG [80], Swiss-Prot [81], KEGG [82], and GO [83]. The KOBAS software with default parameters was used to test the statistical enrichment of differentially expressed genes in KEGG pathways following the methods described by Mao et al. [84].

\section{Differential abundance of LncRNAs}

Cufflinks v2.2.1 software was used to calculate FPKM values associated with lncRNAs and coding genes within each library. The analysis was performed using the EBseq (2010) R package [85]. $P$-values were adjusted to q-values [86]. Only the lncRNAs that met the criteria qvalue $<0.01$ and $\log 2$ (fold change) $>1$ were considered as DALs.

\section{Validation of LncRNAs by PCR}

Seven putative lncRNAs (lncRNA1-7) identified from RNA-seq data were validated using PCR assay (Additional file 9: Table S9). An aliquot of the total RNA used to construct the libraries was reverse-transcribed using a RevertAid First Strand cDNA Synthesis kit (Thermo Scientific $^{\text {tix }}$, Waltham, MA) following the manufacturer's recommendations. Subsequently, the reaction products were diluted 20-fold to serve as the template in a PCR driven by the primer pairs given in Supplementary Table S9. Each $50 \mu \mathrm{L}$ reaction comprised $5 \mu \mathrm{L}$ of $10 \times$ Trans$\mathrm{Taq}^{\circ}$ HiFi Buffer II (Transgen Biotech, Beijing, China),
$4 \mu \mathrm{L}$ of $2.5 \mathrm{mM}$ dNTP (each $10 \mu \mathrm{M}$ ), $1 \mu \mathrm{L}$ of the forward primer and $1 \mu \mathrm{L}$ of the reverse primer (each $10 \mu \mathrm{M}$ ), $4 \mu \mathrm{L}$ of the cDNA template $(50 \mathrm{ng} / \mu \mathrm{L}), 1 \mu \mathrm{L}$ of Trans$\mathrm{Taq}^{\circ} \mathrm{HiFi}$ DNA Polymerase (Transgen Biotech), and $35 \mu \mathrm{L}$ of $\mathrm{dd}_{2} \mathrm{O}$. The amplified product was purified (TIANgel Midi Purification Kit DP209, TIANGEN Biotech, Beijing, China) and subcloned into the pEASY-T1 Cloning Vector (Transgen Biotech) for Sanger sequencing.

\section{Quantification of LncRNAs and target genes abundances using real-time quantitative $P C R$}

The real-time quantitative PCR (RT-qPCR) platform was used to validate the abundance of a selection of the lncRNAs (lncRNA8-20, Supplementary Table S1) and adjacent target genes (Araip.73735, Araip.BU32W, Aradu.K3YEA, Aradu.8P876, Araip.36N6E, Araip.9LF7H, Aradu.NR2UV, Aradu.R9S8R, Aradu.Y8Q46, Aradu.ISE5U, Araip.4W7P2, Araip.WRS65, Araip.WU69J, Supplementary Table S9). We extracted total RNA of the tissues for qRT-PCR using TRIzol reagent (Invitrogen, Carlsbad, CA, USA) and the first-strand cDNA was synthesized by using MMLV reverse transcriptase with random hexamer primers according to the manufacturer's protocol. All RT-qPCR reactions were conducted in triplicates for each cDNA sample using $\mathrm{SYBR}^{\circ}$ Green Realtime PCR Master Mix (TOYOBO, Osaka, Japan) on ABI 7500 FAST real-time PCR platform. The specificity of PCR products was verified through melting curve analysis, and lncRNA and gene expression were quantified by using the $2^{-\Delta \Delta \mathrm{Ct}}$ method, with the abundance of transcript of the gene Actin-1 (XP_015966232.1) used for normalization. The primer sequences are shown in Supplementary Table S1.

\section{AS isoforms validation of LncRNAs by PCR}

Three pair of specific primers (911-F/R, 269-F/R and 806-F/R, Additional file: Table S9) was designed to test for the presence of the AS isoforms of three lncRNA with the same genomic location (TCONS_00217911, Araip.B05 94,398,232-94,402,710; TCONS_00209269, Araip.B05 94,398,710-94,402,916; TCONS_00212806, Araip.B05 94,398,630-94,402,918). A reaction based on KOD-Plus-neo enzyme (TOYOBO, Osaka, Japan) was conducted according to manufacturers' recommendations. After purification, the amplified product was transferred as above for sequencing.

\section{LncRNAs from protein-encoding genes}

A pair of primers (Aradu.Z4DIZ-F/R, Additional file 9: Table S9) was designed to identify the AS isoforms generated from the gene Aradu.Z4DIZ. The PCR was based on the KOD-Plus-neo enzyme (TOYOBO, Osaka, Japan) with $50 \mu \mathrm{L}$ reaction volume following manufacturers' 
instructions. Amplicons were purified and transferred as above and sequenced.

\section{Salt treatment and validation by qRT-PCR}

For salt treatment, peanut seedlings with a uniform growth status (2 weeks old, approximately $8 \mathrm{~cm}$ in height) were treated with $1 \% \mathrm{NaCl}$. Roots and leaves were harvested at $0,0.5,12$, and $24 \mathrm{~h}$ after treatment. The harvested materials were snap-frozen in liquid nitrogen and stored at $-80^{\circ} \mathrm{C}$ until required for RNA extraction. Total RNAs were prepared using a DP441 RNAprep Pure Plant kit (Tiangen, Beijing), and the resulting RNA converted into cDNA using a RevertAid First Strand cDNA Synthesis kit (K1621, Thermo Scientific $^{\mathrm{Tu}}$ ). RT-PCR analyses were conducted in triplicate using $\mathrm{SYBR}^{\circ}$ Green Realtime PCR Master Mix (TOYOBO, Osaka, Japan) on ABI 7500 FAST real-time PCR platform.

Three groups of lncRNAs and their target genes (primers in Additional file 9: Table S9) were used for identification. Each $20 \mu \mathrm{L}$ reaction contained $10 \mu \mathrm{L}$ TaqMan Fast qPCR Master Mix, $0.4 \mu \mathrm{L}$ of each non-labeled primer $(10 \mu \mathrm{M}$ each), $0.4 \mu \mathrm{L}$ of fluorescently-labeled pri-

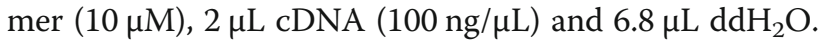
Relative transcript abundances were estimated using the $2^{-\Delta \Delta C T}$ method [87]. Each reaction was run in triplicates for each cDNA sample.

\section{Supplementary information}

Supplementary information accompanies this paper at https://doi.org/10. 1186/s12870-020-02510-4.

Additional file 1: Table S1. Overview of the four total RNA-seq data sets

Additional file 2: Table S2. RNA-seq data production and alignment results of four samples.

Additional file 3: Table S3. The detailed informations of 1442 IncRNAs. Additional file 4: Table S4. 189 differentially expressed IncRNAs.

Additional file 5: Table S5. The distribution of IncRNAs in peanut chromosomes.

Additional file 6: Table S6. Cis-target genes of IncRNAs.

Additional file 7: Table S7. Trans-target genes of IncRNAs.

Additional file 8: Table S8. Integrated function annotation of the target genes.

Additional file 9: Table S9. Primers used in this paper. Additional file 10: Table S10. Comparison with published peanut IncRNAs

Additional file 11: Figure S1. Sequence alignment of seven IncRNAs (IncRNA1-7) with their corresponding RNA-seq sequences.

Additional file 12 Figure S2. Sanger sequencing of five IncRNAs (T1-5). Additional file 13: Figure S3. AS Events of LncRNAs and different AS isoforms had different target genes.

Additional file 14: Figure S4. Sanger sequencing of five IncRNAs (L1.1-1.5).

Additional file 15: Figure S5. The IncRNAs-protein interaction networks.

\section{Abbreviations}

AE: Alternative exon ends; AS: Alternative splicing; DAF: day after flower; DETGs: Differential expressed target genes; ES: Exon skipping; FPKM: Fragments per kilobase of exon per million fragments mapped; Go: Gene Ontology; incRNAs: intronic IncRNAs; IR: Intron retention; KEGG: Sequences Kyoto Encyclopedia of Genes and Genomes; KOG/ COG: Clusters of Orthologous Groups of proteins; lincRNAs: long intergenic ncRNAs; IncRNAs: long noncoding RNAs; miRNAs: microRNAs;

ncRNAs: noncoding RNAs; Nr: non-redundant protein sequences; ORFs: Open reading frames; PCR: Polymerase Chain Reaction; RT-PCR: Reverse Transcription-Polymerase Chain Reaction; TSS: Transcription start site; TTS: Transcription terminal site

\section{Acknowledgments}

We thank Dr. SS (Shandong Peanut Research Institute, Qingdao, China. shansh_spri@163.com) for the gift of their data of peanut IncRNAs.

\section{Authors' contributions}

HT and FG acquired data, JM and HD analyzed and interpreted data, ZZ acquired and analyzed data, XL, SW and ZP participated in design and drafting of the manuscript, revised the manuscript and gave final approval of the version to be published. All authors read and approved the final manuscript.

\section{Funding}

This work was supported by the National Key R\&D Program of China (2018YFD1000900), Major Basic Research Project of Natural Science Foundation of Shandong Province (2018GHZ007), Major Scientific and Technological Innovation Project in Shandong Province (2018YFJH0601), Shandong Province Germplasm Innovation (2017LZN035), Science and Technology Innovation Project of Shandong Academy of Agricultural Sciences (CXGC2018B05, CXGC2018D04, CXGC2018E13).

\section{Availability of data and materials}

Transcriptome raw data of A. hypogaea are available at NCBI project PRJNA354652 with accession number SRR5053815, SRR5054076, SRR5054058 and SRR5054059.

Ethics approval and consent to participate Peanut cultivar 'Fenghua1' was kindly provided by Prof. Yongshan Wan, Shandong Agricultural University. 'Fenghua1' is a good peanut cultivar and widely planted in North China, and the seeds can be bought and sold at will.

Consent for publication

Not applicable.

\section{Competing interests}

The authors declare that they have no competing interests.

\section{Author details}

${ }^{1}$ College of Life Science, Shandong University, Jinan 250014, China. ${ }^{2}$ Bio-Tech Research Center, Shandong Academy of Agricultural Science/Shandong Provincial Key Laboratory of Genetic Improvement, Ecology and Physiology of Crops, Jinan 250014, China. ${ }^{3}$ Peanut Research Institute of Shandong, Qingdao 266100, China. ${ }^{4}$ Shandong Academy of Agricultural Science, Jinan 250014, China.

Received: 9 January 2020 Accepted: 22 June 2020

Published online: 02 July 2020

\section{References}

1. Simms CL, Zaher HS. Quality control of chemically damaged RNA. Cellular and molecular life sciences: CMLS. 2016;73(19):3639-53.

2. Liu J, Jung C, Xu J, Wang H, Deng S, Bernad L, Arenas-Huertero C, Chua NH. Genome-wide analysis uncovers regulation of long intergenic noncoding RNAs in Arabidopsis. Plant Cell. 2012;24(11):4333-45.

3. Chen YA, Aravin AA. Non-coding RNAs in transcriptional regulation: the review for current molecular biology reports. Curr Mol Biol Rep. 2015;1(1): $10-8$. 
4. Ponting CP, Oliver PL, Reik W. Evolution and functions of long noncoding RNAs. Cell. 2009;136(4):629-41.

5. Donaldson ME, Saville BJ. Natural antisense transcripts in fungi. Mol Microbiol. 2012;85(3):405-17.

6. Quan M, Chen J, Zhang D. Exploring the secrets of long noncoding RNAs. Int J Mol Sci. 2015;16(3):5467-96.

7. Liu X, Hao L, Li D, Zhu L, Hu S. Long non-coding RNAs and their biological roles in plants. Genomics, proteomics \& bioinformatics. 2015:13(3):137-47.

8. Chekanova JA. Long non-coding RNAs and their functions in plants. Curr Opin Plant Biol. 2015;27:207-16.

9. Golicz A, Singh MB, Bhalla PL. The long intergenic non-coding RNA (lincRNA) landscape of the soybean genome. Plant Physiol. 2017;176(3): 2133-47.

10. Lukiw WJ, Handley P, Wong L, Crapper McLachlan DR. BC200 RNA in normal human neocortex, non-Alzheimer dementia (NAD), and senile dementia of the Alzheimer type (AD). Neurochem Res. 1992;17(6):591-7.

11. Lv Y, Liang Z, Ge M, Qi W, Zhang T, Lin F, Peng Z, Zhao H: Genome-wide identification and functional prediction of nitrogen-responsive intergenic and intronic long non-coding RNAs in maize (Zea mays L.). BMC Genomics 2016, 17(1):350.

12. McHugh CA, Chen C-K, Chow A, Surka CF, Tran C, McDonel P, PandyaJones A, Blanco M, Burghard C, Moradian A. The Xist IncRNA interacts directly with SHARP to silence transcription through HDAC3. Nature 2015;521(7551):232-6.

13. Stojic L, Niemczyk M, Orjalo A, Ito $Y$, Ruijter AEM, Uribe-Lewis $S$, Joseph N, Weston S, Menon S, Odom DT. Transcriptional silencing of long noncoding RNA GNG12-AS1 uncouples its transcriptional and product-related functions. Nat Commun. 2016;7:10406.

14. Zhang G, Duan A, Zhang J, He C. Genome-wide analysis of long noncoding RNAs at the mature stage of sea buckthorn (Hippophae rhamnoides Linn) fruit. Gene. 2016;596:130-6.

15. Zou C, Wang Q, Lu C, Yang W, Zhang Y, Cheng H, Feng X, Prosper MA, Song $G$. Transcriptome analysis reveals long noncoding RNAs involved in fiber development in cotton (Gossypium arboreum). Sci China Life Sci. 2016; 59(2):164-71.

16. Anderson DM, Anderson $\mathrm{KM}$, Chang $\mathrm{CL}$, Makarewich CA, Nelson BR McAnally JR, Kasaragod P, Shelton JM, Liou J, Bassel-Duby R, et al. A micropeptide encoded by a putative long noncoding RNA regulates muscle performance. Cell. 2015;160(4):595-606.

17. Curtale G, Citarella F. Dynamic nature of noncoding RNA regulation of adaptive immune response. Int J Mol Sci. 2013;14(9):17347-77.

18. Essers PB, Nonnekens J, Goos YJ, Betist MC, Viester MD, Mossink B, Lansu N, Korswagen $H C$, Jelier $R$, Brenkman $A B$, et al. A Long noncoding RNA on the ribosome is required for lifespan extension. Cell Rep. 2015;10(3):339-45.

19. Kadakkuzha BM, Liu XA, McCrate J, Shankar G, Rizzo V, Afinogenova A Young B, Fallahi M, Carvalloza AC, Raveendra B, et al. Transcriptome analyses of adult mouse brain reveal enrichment of IncRNAs in specific brain regions and neuronal populations. Front Cell Neurosci. 2015;9:63.

20. Liz J, Portela A, Soler M, Gomez A, Ling H, Michlewski G, Calin GA, Guil S, Esteller M. Regulation of pri-miRNA processing by a long noncoding RNA transcribed from an ultraconserved region. Mol Cell. 2014:55(1):138-47.

21. Paralkar VR, Weiss MJ. Long noncoding RNAs in biology and hematopoiesis. Blood. 2013;121(24):4842-6.

22. Wang T-Z, Liu M, Zhao M-G, Chen R, Zhang W-H. Identification and characterization of long non-coding RNAs involved in osmotic and salt stress in Medicago truncatula using genome-wide high-throughput sequencing. BMC Plant Biol. 2015;15(1):131.

23. Wang H, Chung PJ, Liu J, Jang IC, Kean MJ, Xu J, Chua NH. Genome-wide identification of long noncoding natural antisense transcripts and their responses to light in Arabidopsis. Genome Res. 2014;24(3):444-53.

24. Ding J, Shen J, Mao H, Xie W, Li X, Zhang Q. RNA-directed DNA methylation is involved in regulating photoperiod-sensitive male sterility in Rice. Mol Plant. 2012;5(6):1210-6.

25. Zhang $H$, Chen $X$, Wang $C, X u Z$, Ji W. Long non-coding genes implicated in response to stripe rust pathogen stress in wheat (Triticum aestivum L.). Molecular Biology Reports. 2013;40(11):6245-53.

26. Li L, Eichten SR, Shimizu R, Petsch K, Yeh CT, Wu W, Chettoor AM, Givan SA, Cole RA, Fowler JE, et al. Genome-wide discovery and characterization of maize long non-coding RNAs. Genome Biol. 2014;15(2):R40.

27. Wang J, Yu W, Yang Y, Li X, Chen T, Liu T, Ma N, Yang X, Liu R, Zhang B: Genome-wide analysis of tomato long non-coding RNAs and identification as endogenous target mimic for microRNA in response to TYLCV infection. Sci Rep 2015, 5(16946)

28. Song X, Sun L, Luo H, Ma Q, Zhao Y, Pei D. Genome-wide identification and characterization of Long non-coding RNAs from mulberry (Morus notabilis) RNA-seq data. Genes (Basel). 2016;7(3):13.

29. Shuai P, Liang D, Tang S, Zhang Z, Ye CY, Su Y, Xia X, Yin W. Genome-wide identification and functional prediction of novel and drought-responsive lincRNAs in Populus trichocarpa. J Exp Bot. 2014;65(17):4975-83.

30. Ding J, Lu Q, Ouyang Y, Mao H, Zhang P, Yao J, Xu C, Li X, Xiao J, Zhang Q. A long noncoding RNA regulates photoperiod-sensitive male sterility, an essential component of hybrid rice. Proc Natl Acad Sci. 2012;109(7):2654-9.

31. Heo JB, Sung S. Vernalization-mediated epigenetic silencing by a long intronic noncoding RNA. Science. 2011;331(6013):76-9.

32. Sun $\mathrm{Q}$, Dean C. R-loop stabilization represses antisense transcription at the Arabidopsis FLC locus. Science. 2013:340(6132):619-21.

33. Ahmed W, Xia Y, Li R, Bai G, Siddique KHM, Guo P. Non-coding RNAs: functional roles in the regulation of stress response in Brassica crops. Genomics. 2019;S0888-7543(18):30626-8.

34. Ma J, Bai X, Luo W, Feng Y, Shao X, Bai Q, Sun S, Long Q, Wan D. Genomewide identification of Long noncoding RNAs and their responses to salt stress in two closely related poplars. Front Genet. 2019:10:777.

35. Wang Z, Jiang $Y$, Wu H, Xie X, Huang B. Genome-wide identification and functional prediction of Long non-coding RNAs involved in the heat stress response in Metarhizium robertsii. Front Microbiol. 2019;10:2336.

36. Zhang X, Dong J, Deng F, Wang W, Cheng Y, Song L, Hu M, Shen J, Xu Q, Shen $F$. The long non-coding RNA IncRNA973 is involved in cotton response to salt stress. BMC Plant Biol. 2019;19(1):459.

37. Qin T, Zhao H, Cui P, Albesher N, Xiong L. A nucleus-localized Long noncoding RNA enhances drought and salt stress tolerance. Plant Physiol. 2017; 175(3):1321-36.

38. Sun $X$, Zheng $H$, Sui N. Regulation mechanism of long non-coding RNA in plant response to stress. Biochem Biophys Res Commun. 2018;503(2):402-7.

39. Zhao X, Gan L, Yan C, Li C, Sun Q, Wang J, Yuan C, Zhang H, Shan S, Liu JN. Genome-wide identification and characterization of Long non-coding RNAs in Peanut. Genes. 2019;10(7):536.

40. Hammons RO: The origin and history of the groundnut. In: The Groundnut Crop. Edited by J S, Smartt J edn. Dordrecht: Springer; 1994: 24-42.

41. Mallikarjuna N, Varshney R. K.: genetics, genomics and breeding of peanut. Boca Raton, FL, USA: CRC Press; 2014.

42. Varshney RK, Pandey MK. Puppala N: [compendium of plant genomes] the Peanut genome $\|$ classical and molecular approaches for mapping of genes and quantitative trait loci in Peanut; 2017.

43. Bertioli DJ, Cannon SB, Froenicke L, Huang G, Farmer AD, Cannon EK, Liu X, Gao D, Clevenger J, Dash S, et al. The genome sequences of Arachis duranensis and Arachis ipaensis, the diploid ancestors of cultivated peanut. Nat Genet. 2016;48(4):438-46.

44. Li S, Yu X, Cheng Z, Zeng C, Li W, Zhang LP, Peng M. Large-scale analysis of the cassava transcriptome reveals the impact of cold stress on alternative splicing. J Exp Bot. 2020;71(1):422-34

45. Lewis BP, Green RE, Brenner SE. Evidence for the widespread coupling of alternative splicing and nonsense-mediated mRNA decay in humans. PNAS. 2003;100(1):189-92.

46. De Quattro C, Mica E, Pe ME, Bertolini E. Brachypodium distachyon Long noncoding RNAs: genome-wide identification and expression analysis Methods Mol Biol. 2018;1667:31-42.

47. Deng F, Zhang X, Wang W, Yuan R, Shen F. Identification of Gossypium hirsutum long non-coding RNAs (IncRNAs) under salt stress. BMC Plant Biol. 2018;18(1):23.

48. Li W, Li C, Li S, Peng M. Long noncoding RNAs that respond to Fusarium oxysporum infection in 'Cavendish' banana (Musa acuminata). Sci Rep. 2017 7(1):16939.

49. Zhang YC, Liao JY, Li ZY, Yu Y, Zhang JP, Li QF, Qu LH, Shu WS, Chen YQ. Genome-wide screening and functional analysis identify a large number of long noncoding RNAs involved in the sexual reproduction of rice. Genome Biol. 2014;15(12):512

50. Reddy AS, Marquez Y, Kalyna M, Barta A. Complexity of the alternative splicing landscape in plants. Plant Cell. 2013;25(10):3657-83.

51. Stamm S, Ben-Ari S, Rafalska I, Tang Y, Zhang Z, Toiber D, Thanaraj TA, Soreq H. Function of alternative splicing. Gene. 2005;344:1-20.

52. Remy E, Cabrito TR, Batista RA, Hussein MA, Teixeira MC, Athanasiadis A, SaCorreia I, Duque P. Intron retention in the 5'UTR of the novel ZIF2 
transporter enhances translation to promote zinc tolerance in arabidopsis. PLoS Genet. 2014;10(5):e1004375.

53. Tang W, Zheng Y, Dong J, Yu J, Yue J, Liu F, Guo X, Huang S, Wisniewski M, Sun J, et al. Comprehensive Transcriptome profiling reveals Long noncoding RNA expression and alternative splicing regulation during fruit development and ripening in kiwifruit (Actinidia chinensis). Front Plant Sci. 2016;7:335.

54. Yang S, Tang F, Zhu H. Alternative splicing in plant immunity. Int J Mol Sci. 2014;15(6):10424-45.

55. Zhang Q, Zhang X, Wang S, Tan C, Zhou G, Li C. Involvement of alternative splicing in barley seed germination. PLoS One. 2016;11(3):e0152824.

56. Ma W, Chen C, Liu Y, Zeng M, Meyers BC, Li J, Xia R. Coupling of microRNAdirected phased small interfering RNA generation from long noncoding genes with alternative splicing and alternative polyadenylation in small RNA-mediated gene silencing. New Phytol. 2018;217(4):1535-50.

57. Yang T, Zhou H, Liu P, Yan L, Yao W, Chen K, Zeng J, Li H, Hu J. Xu H et al: IncRNA PVT1 and its splicing variant function as competing endogenous RNA to regulate clear cell renal cell carcinoma progression. Oncotarget. 2017;8(49):85353-67.

58. Yuan JH, Liu XN, Wang TT, Pan W, Tao QF, Zhou WP, Wang F, Sun SH. The MBNL3 splicing factor promotes hepatocellular carcinoma by increasing PXN expression through the alternative splicing of IncRNA-PXN-AS1. Nat Cell Biol. 2017;19(7):820-32.

59. Milligan MJ, Lipovich L. Pseudogene-derived IncRNAs: emerging regulators of gene expression. Front Genet. 2014;5:476

60. Tay Y, Lev K, Leonardo S, Dror W, Shen Mynn T, Ugo A, Florian K, Laura P, Paolo P, Ferdinando DC et al: Coding-independent regulation of the tumor suppressor PTEN by competing endogenous mRNAs. Cell 2011, 147(2):0-357.

61. Huang JZ, Chen M, Chen D, Gao XC, Zhu S, Huang H, Hu M, Zhu H, Yan GR. A peptide encoded by a putative IncRNA HOXB-AS3 suppresses Colon Cancer growth. Mol Cell. 2017;68(1):171-84.

62. Tajbakhsh S. IncRNA-encoded polypeptide SPAR(s) with mTORC1 to regulate skeletal muscle regeneration. Cell Stem Cell. 2017;20(4):428-30.

63. Park MJ, Seo PJ, Park CM. A self-regulatory circuit of CIRCADIAN CLOCKASSOCIATED1 underlies the circadian clock regulation of temperature responses in Arabidopsis. Plant Cell. 2012;7(9):1194-6.

64. Zhu HQ, Gao FH. The molecular mechanisms of regulation on USP2's alternative splicing and the significance of its products. Int J Biol Sci. 2017; 13(12):1489-96.

65. Zhang QM, Zhao X, Li Z, Wu M, Gui JF, Zhang YB. Alternative splicing transcripts of Zebrafish LGP2 gene differentially contribute to IFN antiviral response. J Immunol. 2018;200(2):688-703.

66. Zaynab M, Fatima M, Abbas S, Umair M, Sharif Y, Raza MA. Long non-coding RNAs as molecular players in plant defense against pathogens. Microb Pathog. 2018:121:277-82.

67. Yang Y, Liu T, Shen D, Wang J, Ling X, Hu Z, Chen T, Hu J, Huang J, Yu W, et al. Tomato yellow leaf curl virus intergenic siRNAs target a host long noncoding RNA to modulate disease symptoms. PLoS Pathog. 2019;15(1): e1007534

68. Yu Y, Zhou YF, Feng YZ, He H, Lian JP, Yang YW, Lei MQ, Zhang YC, Chen $Y Q$ : Transcriptional landscape of pathogen-responsive IncRNAs in rice unveils the role of ALEX1 in jasmonate pathway and disease resistance. Plant Biotechnol J 2019:https://doi.org/10.1111/pbi.13234.

69. Ruan J, Guo F, Wang Y, Li X, Wan S, Shan L, Peng Z: Transcriptome analysis of alternative splicing in peanut (Arachis hypogaea L.). BMC Plant Biol 2018, 18(139).

70. Kim D, Pertea G, Trapnell C, Pimentel H, Kelley R, Salzberg SL. TopHat2: accurate alignment of transcriptomes in the presence of insertions, deletions and gene fusions. Genome Biol. 2013;14(4):R36.

71. Trapnell C, Williams BA, Pertea G, Mortazavi A, Kwan G, van Baren MJ, Salzberg SL, Wold BJ, Pachter L. Transcript assembly and quantification by RNA-Seq reveals unannotated transcripts and isoform switching during cell differentiation. Nat Biotechnol. 2010;28(5):511-5.

72. Kong L, Zhang Y, Ye ZQ, Liu XQ, Zhao SQ, Wei L, Gao G: CPC: assess the protein-coding potential of transcripts using sequence features and support vector machine. Nucleic Acids Research 2007, 69(suppl_2):1-13.

73. Sun L, Luo H, Bu D, Zhao G, Yu K, Zhang C, Liu Y, Chen R, Zhao Y. Utilizing sequence intrinsic composition to classify protein-coding and long noncoding transcripts. Nucleic Acids Res. 2013;41(17):e166.

74. Wang L, Park HJ, Dasari S, Wang S, Kocher JP, Wei L. CPAT: coding-potential assessment tool using an alignment-free logistic regression model. Nucleic Acids Res. 2013;41(6):e74.
75. Finn RD, Bateman A, Clements J, Coggill P, Eberhardt RY, Eddy SR, Heger A, Hetherington K, Holm L, Mistry J, et al. Pfam: the protein families database. Nucleic Acids Res. 2014;42(Database issue):D222-30.

76. Florea L, Song L, Salzberg SL: Thousands of exon skipping events differentiate among splicing patterns in sixteen human tissues. F1000Research 2013, 2:188

77. Jianqin L, Bin W, Jiang X, Chang L, B. Rl: Genome-Wide Identification and Characterization of Long Intergenic Non-Coding RNAs in Ganoderma lucidum. Plos one 2014, 9(6):e99442.

78. Li J, Ma W, Zeng P, Wang J, Geng B, Yang J, Cui Q. LncTar: a tool for predicting the RNA targets of long noncoding RNAs. Brief Bioinform. 2015; 16(5):806-12.

79. $\quad$ Deng YY, Li JQ, Wu SF, Zhu YP, Chen YW, He FC. Integrated nr database in protein annotation system and its localization. Comput Eng. 2006;32(5):71-2

80. Tatusov RL, Galperin MY, Natale DA, Koonin EV. The COG database: a tool for genome-scale analysis of protein functions and evolution. Nucleic Acids Res. 2000;28(1):33-6.

81. Apweiler R, Bairoch A, Wu CH, Barker WC, Boeckmann B, Ferro S, Gasteiger E, Huang H, Lopez R, Magrane M, et al. UniProt: the universal protein knowledgebase. Nucleic Acids Res. 2004;45(D1):D158-69.

82. Kanehisa M, Goto S, Kawashima S, Okuno Y, Hattori M. The KEGG resource for deciphering the genome. Nucleic Acids Res. 2004;32(Database issue): D277-80.

83. Ashburner M, Ball CA, Blake JA, Botstein D, Butler H, Cherry JM, Davis AP, Dolinski K, Dwight SS, Eppig JT, et al. Gene ontology: tool for the unification of biology. Nat Genet. 2000;25(1):25-9.

84. Mao X, Cai T, Olyarchuk JG, Wei L. Automated genome annotation and pathway identification using the KEGG Orthology (KO) as a controlled vocabulary. Bioinformatics. 2005;21(19):3787-93.

85. Leng N, Dawson JA, Thomson JA, Ruotti V, Rissman Al, Smits BMG, Haag JD, Gould MN, Stewart RM, Kendziorski C. EBSeq: an empirical Bayes hierarchical model for inference in RNA-seq experiments. Bioinformatics. 2013;29(8): 1035-43.

86. Storey JD. The positive false discovery rae: a bayesian interpretation and the q-value. Ann Stat. 2003:31(6):2013-35.

87. Livak KJ, Schmittgen TD. Analysis of relative gene expression data using real-time quantitative PCR and the $2^{-\Delta \Delta C T}$ method. Methods. 2001;25:402-8.

\section{Publisher's Note}

Springer Nature remains neutral with regard to jurisdictional claims in published maps and institutional affiliations.

Ready to submit your research? Choose BMC and benefit from:

- fast, convenient online submission

- thorough peer review by experienced researchers in your field

- rapid publication on acceptance

- support for research data, including large and complex data types

- gold Open Access which fosters wider collaboration and increased citations

- maximum visibility for your research: over $100 \mathrm{M}$ website views per year

At $\mathrm{BMC}$, research is always in progress.

Learn more biomedcentral.com/submissions 